\title{
Effects of laparoscopy, laparotomy, and respiratory phase on liver volume in a live porcine model for liver resection
}

\author{
Hannes G. Kenngott ${ }^{1} \cdot$ Felix Nickel $^{1}$ - Anas A. Preukschas ${ }^{1}$ - Martin Wagner ${ }^{1}$ - Shivalik Bihani ${ }^{1}$ - Emre Özmen ${ }^{1}$. \\ Philipp A. Wise ${ }^{1} \cdot$ Nadine Bellemann ${ }^{2}$. Christof M. Sommer ${ }^{2} \cdot$ Tobias Norajitra $^{3}$ - Bastian Graser ${ }^{3}$. Christian Stock ${ }^{4}$. \\ Marco Nolden ${ }^{3}$. Araineb Mehrabi ${ }^{1} \cdot$ Beat P. Müller-Stich ${ }^{1}{ }^{\circledR}$
}

Received: 23 June 2020 / Accepted: 3 December 2020 / Published online: 4 January 2021

(c) The Author(s) 2020

\begin{abstract}
Background Hepatectomy, living donor liver transplantations and other major hepatic interventions rely on precise calculation of the total, remnant and graft liver volume. However, liver volume might differ between the pre- and intraoperative situation. To model liver volume changes and develop and validate such pre- and intraoperative assistance systems, exact information about the influence of lung ventilation and intraoperative surgical state on liver volume is essential.

Methods This study assessed the effects of respiratory phase, pneumoperitoneum for laparoscopy, and laparotomy on liver volume in a live porcine model. Nine CT scans were conducted per pig $(N=10)$, each for all possible combinations of the three operative (native, pneumoperitoneum and laparotomy) and respiratory states (expiration, middle inspiration and deep inspiration). Manual segmentations of the liver were generated and converted to a mesh model, and the corresponding liver volumes were calculated.

Results With pneumoperitoneum the liver volume decreased on average by $13.2 \%(112.7 \mathrm{ml} \pm 63.8 \mathrm{ml}, p<0.0001)$ and after laparotomy by $7.3 \%(62.0 \mathrm{ml} \pm 65.7 \mathrm{ml}, p=0.0001)$ compared to native state. From expiration to middle inspiration the liver volume increased on average by $4.1 \%(31.1 \mathrm{ml} \pm 55.8 \mathrm{ml}, p=0.166)$ and from expiration to deep inspiration by $7.2 \%(54.7 \mathrm{ml} \pm 51.8 \mathrm{ml}, p=0.007)$.

Conclusions Considerable changes in liver volume change were caused by pneumoperitoneum, laparotomy and respiration. These findings provide knowledge for the refinement of available preoperative simulation and operation planning and help to adjust preoperative imaging parameters to best suit the intraoperative situation.
\end{abstract}

Keywords Operation planning $\cdot$ Soft tissue surgery $\cdot$ Respiratory phase $\cdot$ Liver volume $\cdot$ Computer assistance $\cdot$ Navigation

Beat P. Müller-Stich

beat.mueller@med.uni-heidelberg.de

1 Department of General, Visceral and Transplantation Surgery, Heidelberg University, Im Neuenheimer Feld 110, 69120 Heidelberg, Germany

2 Department of Diagnostic and Interventional Radiology, Heidelberg University, Im Neuenheimer Feld 110, 69120 Heidelberg, Germany

3 Division of Medical and Biological Informatics, German Cancer Research Center, Im Neuenheimer Feld 280, 69120 Heidelberg, Germany

4 Institute of Medical Biometry and Informatics, Heidelberg University, Im Neuenheimer Feld 130.3, 69120 Heidelberg, Germany

\author{
Abbreviations \\ LDLT Living donor liver transplantation \\ CT Computed tomography \\ DICOM Digital Imaging and Communications in \\ Medicine \\ MITK Medical Imaging Interaction Toolkit
}

Safe performance of hepatectomy, living donor liver transplantations (LDLT) and other major hepatic interventions rely on preoperative calculation and estimation of total and residual liver and graft volume. Liver resections are required to respect the anatomical segmentation of the liver, safety margins in oncological surgery, and resection lines guaranteeing that the residual liver volume and function is sufficient and oncological outcomes are adequate [1,2]. Preoperative calculation and simulation of liver volume can assist the 
surgeon in identifying safe operation strategies with respect to the individual vascular, segmental and oncological characteristics [3]. Furthermore, intraoperative navigation may facilitate three-dimensional orientation of the surgeon and promises to help in the identification of at-risk structures and safe resection lines [4]. Navigation may be of particular benefit in minimally invasive surgery [5] where it may help compensate for the additional difficulties of the confined space of pneumoperitoneum, two-dimensional representation of the operating field and the unintuitive instrument handling. Intraoperative navigation requires a precise alignment of the preoperative imaging data to the intraoperative situation [5, 6]. In abdominal surgery, soft tissue movement and deformation causes the organs to change considerably in form, position and size [7]. These changes are the result of positioning [8], respiration [9], pneumoperitoneum [10], tissue dissection and iatrogenic manipulation $[11,12]$. To compensate for this phenomenon there are two approaches: Intraoperative imaging and other methods of tissue localization $[5,6,11,13,14]$, or biomechanical modeling, which tries to predict the tissue deformation based on calculations of the factors responsible for the deformation.

Here we report on a study with the following aims: 1 . to analyze and quantify the influence of laparotomy and pneumoperitoneum for laparoscopy on liver volume; 2 . to assess the effect of different inspiratory volumes on liver volume in the different operative states.

\section{Materials and methods}

\section{Subjects}

A total of ten pigs (German landrace, 20-34 kg) were analyzed. The study protocol was approved by the local Ethics Committee in Heidelberg, Germany and by the regional committee in Karlsruhe, Germany. The care and veterinary handling were carried out by the staff of the Interfaculty Biomedical Research Facility at Heidelberg University and complied with the recommendations outlined in the "Guide for the Care and Use of Laboratory Animals" prepared by the National Academy of Sciences and published by the National Institutes of Health [15].

The animals were fasted $12 \mathrm{~h}$ before the intervention. A modified anesthesia protocol was used based on Clutton et al. [16]. After premedication with azaperone $(0.1 \mathrm{mg} /$ $\mathrm{kg})$, midazolam $(0.1 \mathrm{mg} / \mathrm{kg})$ and ketamine $(15 \mathrm{mg} / \mathrm{kg})$, the induction of anesthesia was carried out by intravenous midazolam $(0.1 \mathrm{mg} / \mathrm{kg})$ and ketamine $(20 \mathrm{mg} / \mathrm{kg})$. Anesthesia was maintained with intravenous midazolam $(0.05 \mathrm{mg} / \mathrm{kg})$ and ketamine $(10 \mathrm{mg} / \mathrm{kg})$. Pancuronium was used as needed. The animals were machine ventilated $(f=12 / \mathrm{min}$, ventilation volume $=250-320 \mathrm{ml}$ ). The animals were positioned in a $0^{\circ}$ supine position on a vacuum mattress which was firmly attached to a stretcher. This stretcher and vacuum mattress combination guaranteed full immobilization of the animal between scans [17]. The animals on the stretcher were left in place on a fixed position on the CT scan table for the entire duration of the experiments to rule out repositioning errors. The animals were under general anesthesia with machine ventilation during the entire experiments. At the end of the study the animals were euthanized using potassium chloride $(150 \mathrm{mg} / \mathrm{kg})$ as per protocol.

\section{Study design}

Each pig was examined by Computed Tomography (CT) in nine different states. The CT scans were obtained for three respiratory states (full expiration, middle inspiration and deep inspiration) in each of three operative states (native, pneumoperitoneum and laparotomy). The CT scans were taken with a slice thickness of $2 \mathrm{~mm}$ and a $1 \mathrm{~mm}$ overlay with the SOMATOM Sensation ${ }^{\mathrm{TM}} 64$ Row Dual Energy CT device (Siemens Corp. Erlangen, Germany). Before imaging $50 \mathrm{ml}$ of the contrast agent Imeron ${ }^{\circledR} 300$ (Bracco Imaging Deutschland GmbH, Konstanz, Germany) was intravenously administered. CT scans were acquired $120 \mathrm{~s}$ after application of the contrast agent, which corresponded to the venous phase. For each respiratory state manually controlled breath-hold positions were realized. End-expiratory hold maneuver was performed to maintain full expiration. Our definitions for high tidal volume was $14 \mathrm{ml} / \mathrm{kg}$ (deep inspiration, approximately $400 \mathrm{ml}$ ) and for middle tidal volume was $7 \mathrm{ml} / \mathrm{kg}$ (normal inspiration, approximately $200 \mathrm{ml}$ ) based on previous studies [18-20]. Both inspiratory levels were maintained by occluding the respiratory port once the tidal volume was reached.

The pneumoperitoneum for laparoscopy was created using a Veress-needle (14-gauge) in the left lower quadrant of the abdomen. A standard pressure-controlled insufflation device was used to maintain an intra-abdominal pressure of $15 \mathrm{mmHg}$ with $\mathrm{CO}_{2}$-insufflation. After imaging was completed with pneumoperitoneum the Veress-needle was removed and a standard midline laparotomy of $20 \mathrm{~cm}$ length was performed using a disposable scalpel. The data from the CT scans were transferred onto a mobile hard disk for the following evaluation. All pictures complied with the Digital Imaging and Communications in Medicine (DICOM) standard.

\section{Image processing and segmentation}

The imaging data were post-processed using the Medical Imaging Interaction Toolkit (MITK) which was developed by the Division of Medical and Biological Informatics at the German Cancer Research Center in Heidelberg [21]. 
The segmentation process consisted of manually circumscribing the liver tissue in the transversal view for one slice in every eight slices. The slices between the manually segmented slices were interpolated by the MITK software (Fig. 1). Detailed information on the interpolation algorithm can be found in the MITK documentation [22]. The interpolated slices were checked manually and additional slices were manually segmented if the interpolation was not accurate. The vena cava, the extrahepatic portal vein and the gall bladder were consistently excluded from the segmentations. The end result was checked for correctness in each slice and in all three views (transversal, sagittal and coronal). Image segmentation was performed and cross-checked by two independent and specially trained professionals. Threedimensional mesh models were generated from the segmentations of the liver using the MITK software. For each mesh model the corresponding volume was calculated using the open-source software MeshLab which was developed by the Italian Institute of Information Science and Technology and the Italian National Research Council. We used MeshLabs "Compute Geometric Measures" function [23].

\section{Statistical analysis}

The data were evaluated using a hierarchical linear regression [24]. We examined the influence of the operative state
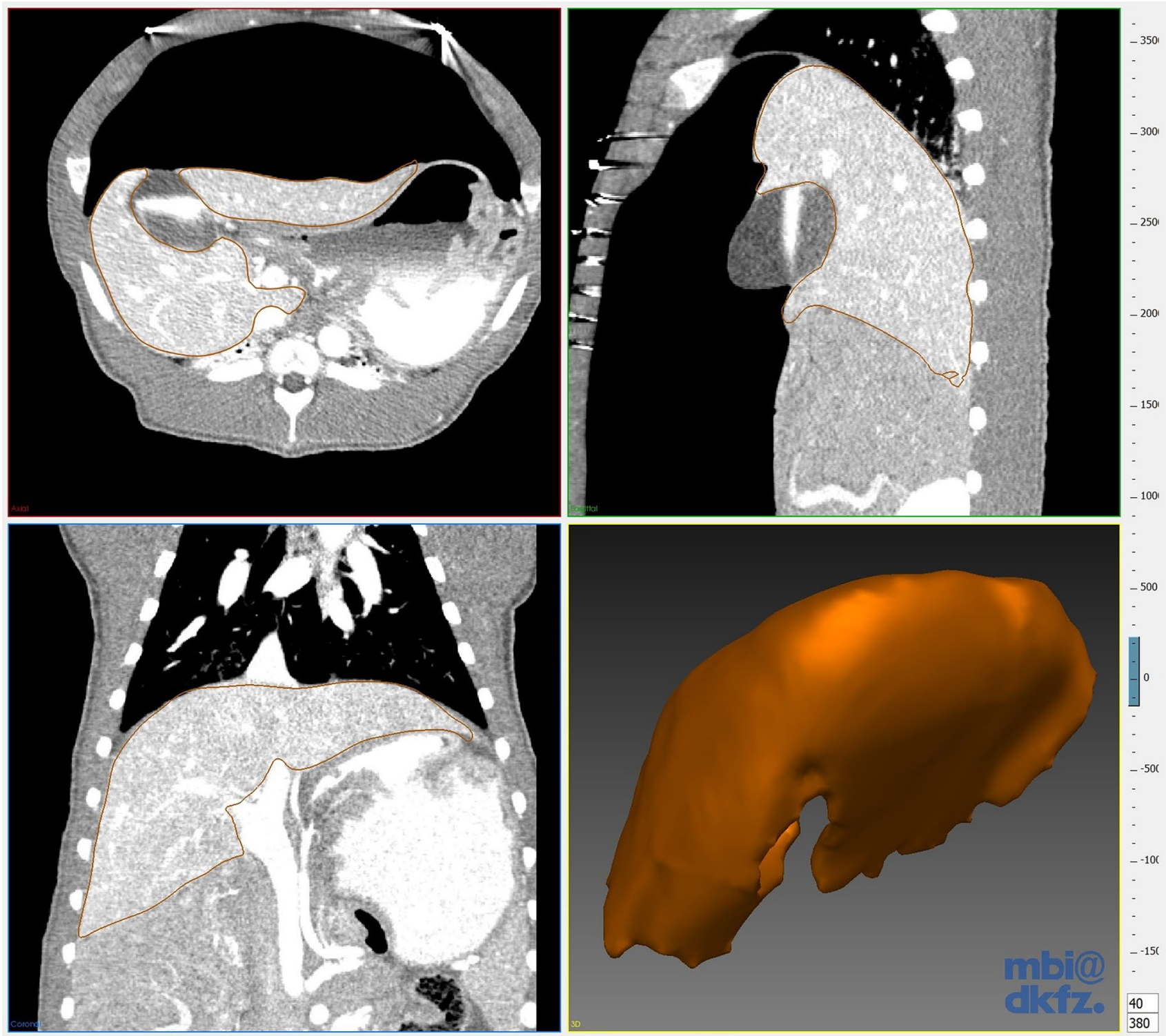

Fig. 1 Manual segmentation of a computed tomography scan of the porcine liver with pneumoperitoneum in the Medical Imaging Interaction Toolkit (MITK). Axial view (top left), Sagittal view (top

right), Coronal view (bottom left) and three-dimensional model based on the segmentations (bottom right) 
(native, laparotomy, pneumoperitoneum) and the respiratory state (continuous predicator with levels expiration, middle inspiration and full inspiration) on the measured liver volumes. We analyzed liver volume changes depending on the operative state based on the interaction between operative state and respiratory state. Liver volumes of each animal were considered with a random factor. The data were indicated as mean \pm standard deviation, if not otherwise specified. Significance level was set to $\alpha=5 \%$ two-sided, without correction for multiple testing. Graphs were created using the plotrix package for R (R Foundation for Statistical Computing, Vienna, Austria).

\section{Results}

\section{Total liver volume}

The mean liver volume over all measurements was $792.9 \pm 96.1 \mathrm{ml}$ (minimum: $644.3 \mathrm{ml}$; maximum: $1034.6 \mathrm{ml})$.

\section{Operative state}

The mean volume in the native state was $851.0 \mathrm{ml} \pm 92.8 \mathrm{ml}$ (minimum: $666.0 \mathrm{ml}$; maximum: $1034.6 \mathrm{ml}$ ), with pneumoperitoneum it was $738.4 \mathrm{ml} \pm 75.1 \mathrm{ml}$ (minimum: $651.7 \mathrm{ml}$; maximum: $895.4 \mathrm{ml}$ ) and after laparotomy it was $789.1 \mathrm{ml} \pm 86.5 \mathrm{ml}$ (minimum: $644.3 \mathrm{ml}$ and Maximum: $1002.3 \mathrm{ml}$ ). With pneumoperitoneum the liver volume decreased by $13.2 \%$ or $112.7 \mathrm{ml} \pm 63.9 \mathrm{ml}(95 \%$-CI 88.9-136.6 ml, $p<0.0001)$ compared to the native state. After midline laparotomy the liver volume was still reduced by $7.3 \%$, or $62.0 \mathrm{ml} \pm 65.7 \mathrm{ml}(95 \%$-CI $37.4-86.5 \mathrm{ml}$, $p=0.0001)$ compared to the native state but was not significantly higher than with pneumoperitoneum $(p=0.18$ (Fig. 2).

\section{Respiratory state}

The mean volume with full expiration was $764.3 \mathrm{ml} \pm 95.1 \mathrm{ml}$ (minimum: $644.3 \mathrm{ml}$; maximum: $1034.6 \mathrm{ml}$ ), with middle inspiration it was $795.4 \mathrm{ml} \pm 90.9 \mathrm{ml}$ (minimum: $663.9 \mathrm{ml}$ and Maximum: $971.5 \mathrm{ml}$ ) and with full inspiration it was $818.9 \mathrm{ml} \pm 97.2 \mathrm{ml}$ (minimum: $659.7 \mathrm{ml}$ and Maximum: $1019.2 \mathrm{ml}$ ). Inspiratory volumes had a significant influence on liver volume. With middle inspiration liver volume increased by $4.1 \%$ or $31.1 \mathrm{ml} \pm 55.8 \mathrm{ml}(95 \%$-CI $10.3-51.9 \mathrm{ml}, p=0.166)$ and with full inspiration by $7.2 \%$ or $54.7 \mathrm{ml} \pm 51.8 \mathrm{ml}$ compared to expiration (95\% CI 35.4-74.1 $\mathrm{ml}, p=0.007$ ) (Fig. 2).

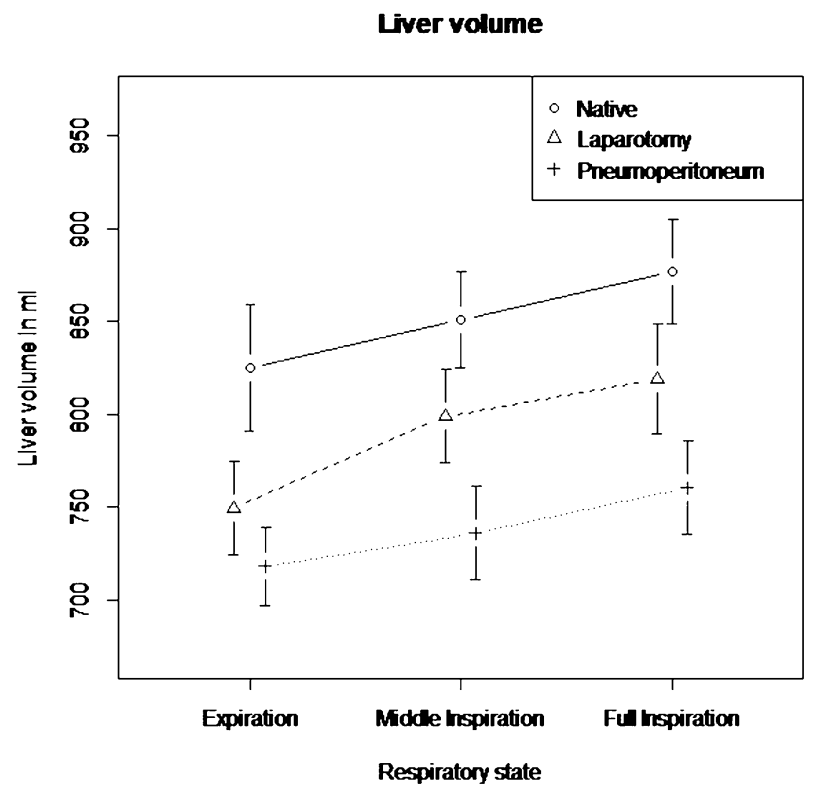

Fig. 2 Liver volume stratified by operative and respiratory state in milliliters $(\mathrm{ml})($ mean \pm standard error $)$

\section{Discussion}

Laparotomy, Pneumoperitoneum and respiratory states had a significant influence on liver volume. Compared to the native state the liver volume decreased most with pneumoperitoneum (13.2\%) and less after midline laparotomy (7.3\%). With full inspiration liver volume increased more (7.2\%) than with middle inspiration (4.1\%) compared to expiration. The highest change in liver volume was produced by pneumoperitoneum in the present study. Earlier studies showed that liver volume may vary up to $33 \%$ between perfused and non-perfused livers [25-27]. In the literature several cardiovascular changes are reported with pneumoperitoneum: decreased cardiac output and stroke volume, decreased venous return, increase of systemic resistance and adverse splanchnic circulatory effects [28, 29]. Concerning the liver, decreased hepatic perfusion has been reported with pneumoperitoneum [30-32]. Decreased portal [33-35] and hepatic [36-39] blood flow was reported in several studies, although some studies did not find significant change of portal flow $[30,40]$. The diameter of the portal vein and mean luminal area of the portal vein were also found decreased in other studies, which is consistent with a decrease of the portal vein flow with pneumoperitoneum $[41,42]$. The pressure of the pneumoperitoneum was also shown to decrease the diameter of the Inferior vena cava [43-46] and to cause a decrease of the blood flow in the vena cava [42]. These factors are in line with a decreased blood volume in the liver during pneumoperitoneum which likely caused the decrease liver volume. One possible explanation is that the pressure created 
in the abdominal cavity lead to a decrease in hepatic perfusion which finally caused the consistent decrease in liver volume. A study by Moyano-Cuevas et al. [41] described an increase of liver volume after insufflating the abdomen with $14 \mathrm{mmHg}$ of $\mathrm{CO}_{2}$. This contradicts our findings; however, our results seem to be more in line with the cardiovascular and other abdominal changes occurring during pneumoperitoneum [46].

The reduction in liver size from native volume to laparoscopy is most likely explained from the increase in intraabdominal pressure during laparoscopy. However, the reduction in volume between native state and laparotomy was an unexpected result. To better assess the change in intraabdominal pressure differences between the three modalities of native, laparoscopic and open, a follow-up experiment was conducted whereby the intra-abdominal pressure was measured via bladder catheter, at five measurements per operative state per subject $(n$ per state $=25$ ). The results are summarized in Table 1 and show a significant difference in intra-abdominal pressure between both native state and pneumoperitoneum, and laparotomy and pneumoperitoneum. The change in liver volume in laparotomy could also be an effect of the physiological surgical stress response, as sympathetic activation could lead to decreased perfusion of the liver [47-49]. A further possible reason for a smaller volume during laparotomy is due to the sequence in which the measurements were conducted. As median laparotomy was performed after pneumoperitoneum, the liver volume had already been reduced through the increased intra-abdominal pressure. Whether this was the causative factor, however, was not assessed because no further CT scans were performed after prolonged laparotomy to check for a possible later increase in liver volume. This is certainly a limitation of the current study, and should be taken into consideration when designing future experiments attempting to evaluate differences in surgical modalities. It nevertheless does not detract from the main argument of the current study that liver volume is decreased by increased intra-abdominal pressure, and is a further indication that the pneumoperitoneum decreases perfusion, which would require more time to return to previous volume than simple tissue displacement or compression.

Liver volume change after laparotomy has been studied for discrepancies between preoperatively calculated and intraoperatively measured liver graft volumes in liver transplantation. Lemke et al. found a conversion factor for calculated graft weight and actual graft weight ( 0.75 of virtual measurement) of the non-perfused graft which improved measurement accuracy [50]. Karlo et al. found a conversion factor for CT ( 0.85 of virtual measurement) and MRI (0.78 of virtual measurement) to adjust preoperatively calculated resection volumes to actual intraoperative resection volume [51]. This compares similar to our findings of $13.2 \%$ (pneumoperitoneum vs native expiration) and 7.3\% (laparotomy vs native expiration) changes in liver volume. The volume decrease in the present study was expectedly less than in the aforementioned studies by Karlo and Lemke since the present study was completed in situ in perfused organs versus the resected non-perfused organs in above mentioned studies. These findings should be discussed regarding clinical relevance. Primarily, liver volume as measured preoperatively is the metric used when deciding safe resection volumes in partial hepatectomies, as well as determining adequate volumes for transplantation surgery. Guidelines exist with cut-offs and recommendations for safe resection/transplantation, but these are also dependent on surgeon experience and individual consideration. Changes in liver volume between native state, laparoscopy, and laparotomy will in the future be important with the introduction of intraoperative imaging and assistance systems that aim for high resolution estimates of postoperative outcomes, e.g., of future remnant liver volume. This accuracy will then also depend on the intraoperative change of liver volume depending on the mode of surgery. A change in liver volume of up to $13 \%$ in the current study would be important to consider when critical decisions have to be made regarding resectability or alternative treatment strategies. The clinical application hence lies in the influence on intraoperative decision-making and the influence on surgical outcome, such as overestimating liver remnant volume in resection or misjudging

Table 1 Comparison of intravesicular pressure of the measured operative states

\begin{tabular}{llrr}
\hline Intravesicular pressure $(n=75)$ & Native & Pneumoperitoneum & Laparotomy \\
\hline Mean pressure $[\mathrm{mmHg}]$ & 5.95 & 11.73 & 7.08 \\
Standard deviation $[\mathrm{mmHg}]$ & 1.68 & 1.80 & 2.68 \\
\hline Comparison & $p$ value & & \\
\hline Native vs pneumoperitoneum & $<\mathbf{0 . 0 0 1}$ & & \\
Native vs Laparotomy & 0.059 & & \\
Pneumoperitoneum vs laparotomy & $\mathbf{0 . 0 0 1}$ &
\end{tabular}

Significant $p$-values in bold 
functional size of live donor liver segments in preoperative planning. On the other hand, the use of navigation systems with intraoperative tracking and segmentation of liver volume and position according to preoperative images would also be influenced by changes in liver volume, form, and position. In regards to preoperative planning, differences in preoperative measured volume and in situ volume have been recorded previously. In volumetric analysis of living donor transplant livers, Baskiran et al. described significant reductions between estimated and intraoperative volumes [52], and correctly stressed the need for surgical awareness to prevent small-for-size and large-for-size errors. The current study should underline this finding, and further emphasize that liver volume must be critically re-evaluated in the intraoperative setting, especially in laparoscopic procedures.

Liver volume increased with inspiration in the present study. A possible explanation of the increase in volume could be the decrease of central venous return and thus a decrease of venous return from the liver blood pool due to the positive pressure ventilation mandatory with general anesthesia in this experimental model [53]. However, other studies showed no significant effect of mechanical ventilation and positive end-expiratory pressure on liver blood flow [54-56]. The reason for this discrepancy therefore warrants further investigation.

A further clinical aspect to be discussed would be a critical evaluation of preoperative liver CT scans in regards to resection planning. Currently, CTs are performed at maximal inspiration. This may result in the liver measurements being significantly larger than in situ intraoperatively, and could result in overestimation of either required resection area or of the volume of the remaining liver. A possible clinical recommendation could be to perform the $\mathrm{CT}$ at maximal expiration for better preoperative assessment of liver volume; however, the small sample size and experimental nature of the current study limit a direct clinical translation. Further evaluation in a clinical setting would be warranted when intraoperative imaging modalities with volumetric assessment become more widely available, such as intraoperative CT or MRI imaging. The current study however shows that such studies should be performed in humans to avoid a mismatch between preoperative planning and intraoperative situations in such future scenarios.

Additionally, a significant change in volume and liver perfusion may also result in a significant shifting of structures in the liver, such as the exact location of vessels or tumor. While an exact measurement and segmentation of critical structures extends beyond the scope of the current study, the establishment of the large change in volume provides adequate basis for this question to be evaluated in future experiments.

The present study was performed using a live porcine model, because it shows highest similarity to human anatomy. Still the porcine liver shows some noteworthy differences to the human one: it has four lobes instead of two and these can be flatter than in humans. Moreover, the porcine liver exhibits a different segmental nature [57]. Organ size was comparable to humans but less than in most western adult human livers [58]. The porcine model is well established in studies regarding the evaluation of the effects of pneumoperitoneum and for liver volumetry [7], whereas specific effects of respiration, pneumoperitoneum and laparotomy on liver volume had not been studied in detail in this model $[25,26,33-35,41,59]$. The application of the results in this study must be evaluated critically before using them in a clinical environment. The experimental nature of this study in a porcine model unfortunately results in a small study population $(n=10)$, and the resulting large confidence intervals must be acknowledged as a weakness. Nevertheless, the study showed a statistically significant change between all three measurements, as well as a statistically significant difference in liver volume between inspiratory and expiratory states. These results form the basis of the arguments put forth in this discussion, and other studies assessing preoperative planning and intraoperative volume show corroborating evidence $[25,51,52,58,60-62]$. Consistent with the recommendations to keep the number of animal experiments as low as possible, e.g., 3Rs (reduction, replacement, refinement) and PREPARE guidelines we chose to not perform additional experiments since the current number of animals was sufficient for statistical evaluation with the current focus of the study.

The gold standard for volumetry is water displacement of Archimedes, but as this is only possible with an explanted liver, we could not use this method. We used CT scans to assess liver volume as it is used as gold standard to preoperatively determine liver volume [60, 63, 64]. Image-based volumetric techniques especially regarding the measurement of liver volume are considered reliable and accurate [26, 58, 65-68]. Some studies however have shown that CT and MRI based methods seem to over- and underestimate in vivo liver volume from actual graft volume. These differences seem to be caused by measurements in different perfusion states and by inconsistencies in the method of image segmentation [61, 62, 69-74]. We used manual image segmentation of CT scans with semiautomated interpolation, as it provided accurate and consistent results and is used as the reference standard in many studies [26, 27, 57, 72, 75]. Nonetheless, intraobserver variability of up to $5 \%$ is reported, making the manual input a source of possible errors. The method of determining the inspiratory volumes was limited in that the respiration volume was defined by estimation and determined by visual control on the ventilation machine. A brief statement should be made here that the results of this study reflect respiratory states in mechanical ventilation, and not spontaneous respiration. However, for the purposes of the 
clinical applicability, this should not be seen as a large weakness of the study. The two main arguments of clinical relevance of this study stem from intraoperative assessment of resection volumes and from preoperative planning with CT images. In the case of intraoperative assessment, mechanical ventilation is an appropriate modality for the study. In preoperative CT scans, a breath hold will result in static intrathoracic pressure similar to the respiratory port occlusion used in the current study, however it must be noted that this is an approximation of the measurement, and not an exact replication of the clinical setting.

In conclusion, our results show that liver volume is influenced intraoperatively by pneumoperitoneum and laparotomy as well as by different inspiratory volumes. Changes of up to $13.2 \%$ in liver volume were found in the present experimental model between the pre- and intraoperative situation. Preoperative calculations and intraoperative navigation for major hepatic interventions should be done with consideration to these changes in volume. Furthermore, the results of this study can be used to help refine intraoperative navigation systems in hepatic surgery and interventions.

Author contributions Study conception and design: M-Stich, Nickel, Kenngott, Mehrabi, Acquisition of data: Nickel, Gehrig, Sommer, Bellemann, Kenngott, Preukschas, Özmen, Bihani, Wise, Graser, Norajitra, Wagner, Nolden Statistical analysis: Stock, Preukschas, Norajitra, Graser. Analysis and interpretation of data: Nickel, Müller-Stich, Kenngott, Stock, Mehrabi, Bellemann, Özmen, Bihani, Preukschas, Nolden. Drafting of manuscript: Nickel, Kenngott, Wise. Critical revision: Müller-Stich, Mehrabi, Sommer.

Funding Open Access funding enabled and organized by Projekt DEAL. The current study was conducted in the setting of Research Group 1126: "Development of New Computer-Based Methods for the Future Workplace in Surgery" funded by the German Research Foundation (DFG).

\section{Compliance with ethical standards}

Disclosure Felix Nickel reports receiving travel support for conference participation as well as equipment provided for laparoscopic surgery courses by KARL STORZ, Johnson \& Johnson, Medtronic, Intuitive Surgical, Cambridge Medical Robotics, as well as consultancy fees from KARL STORZ. Hannes G. Kenngott, Anas A. Prekuschas, Shivalik Bihani, Emre Özmen, Martin Wagner, Philipp A. Wise, Marco Nolden, Nadine Bellemann, Christof Sommer, Tobias Norajitra, Bastian Graser, Christian Stock, Arianeb Mehrabi, and Beat Peter MüllerStich have no conflicts of interest or financial ties to disclose.

Open Access This article is licensed under a Creative Commons Attribution 4.0 International License, which permits use, sharing, adaptation, distribution and reproduction in any medium or format, as long as you give appropriate credit to the original author(s) and the source, provide a link to the Creative Commons licence, and indicate if changes were made. The images or other third party material in this article are included in the article's Creative Commons licence, unless indicated otherwise in a credit line to the material. If material is not included in the article's Creative Commons licence and your intended use is not permitted by statutory regulation or exceeds the permitted use, you will need to obtain permission directly from the copyright holder. To view a copy of this licence, visit http://creativecommons.org/licenses/by/4.0/.

\section{References}

1. Emond JC, Renz JF, Ferrell LD, Rosenthal P, Lim RC, Roberts JP, Lake JR, Ascher NL (1996) Functional analysis of grafts from living donors. Implications for the treatment of older recipients. Ann Surg 224:544-552

2. Kiuchi T, Kasahara M, Uryuhara K, Inomata Y, Uemoto S, Asonuma K, Egawa H, Fujita S, Hayashi M, Tanaka K (1999) Impact of graft size mismatching on graft prognosis in liver transplantation from living donors. Transplantation 67:321-327

3. Hallet J, Gayet B, Tsung A, Wakabayashi G, Pessaux P (2015) Systematic review of the use of pre-operative simulation and navigation for hepatectomy: current status and future perspectives. J Hepatobiliary Pancreat Sci 22:353-362

4. Najmaei N, Mostafavi K, Shahbazi S, Azizian M (2012) Imageguided techniques in renal and hepatic interventions. Int J Med Robot 9:379-395

5. Kenngott HG, Wagner M, Gondan M, Nickel F, Nolden M, Fetzer A, Weitz J, Fischer L, Speidel S, Meinzer HP, Bockler D, Buchler MW, Muller-Stich BP (2014) Real-time image guidance in laparoscopic liver surgery: first clinical experience with a guidance system based on intraoperative CT imaging. Surg Endosc 28:933-940

6. Mersmann S, Seitel A, Erz M, Jahne B, Nickel F, Mieth M, Mehrabi A, Maier-Hein L (2013) Calibration of time-of-flight cameras for accurate intraoperative surface reconstruction. Med Phys 40:082701

7. Nickel F, Kenngott HG, Neuhaus J, Andrews N, Garrow C, Kast J, Sommer CM, Gehrig T, Gutt CN, Meinzer HP, Muller-Stich BP (2018) Computer tomographic analysis of organ motion caused by respiration and intraoperative pneumoperitoneum in a porcine model for navigated minimally invasive esophagectomy. Surg Endosc 32:4216-4227

8. Lafon Y, Smith FW, Beillas P (2010) Combination of a modeldeformation method and a positional MRI to quantify the effects of posture on the anatomical structures of the trunk. J Biomech 43:1269-1278

9. Bussels B, Goethals L, Feron M, Bielen D, Dymarkowski S, Suetens P, Haustermans K (2003) Respiration-induced movement of the upper abdominal organs: a pitfall for the three-dimensional conformal radiation treatment of pancreatic cancer. Radiother Oncol 68:69-74

10. Zijlmans M, Langø T, Hofstad EF, Van Swol CFP, Rethy A (2012) Navigated laparoscopy-liver shift and deformation due to pneumoperitoneum in an animal model. Minim Invasive Ther Allied Technol 21:241-248

11. Kenngott HG, Wagner M, Nickel F, Wekerle AL, Preukschas A, Apitz M, Schulte T, Rempel R, Mietkowski P, Wagner F, Termer A, Muller-Stich BP (2015) Computer-assisted abdominal surgery: new technologies. Langenbecks Arch Surg 400:273-281

12. Nickel F, Kenngott HG, Neuhaus J, Sommer CM, Gehrig T, Kolb A, Gondan M, Radeleff BA, Schaible A, Meinzer HP, Gutt CN, Muller-Stich BP (2013) Navigation system for minimally invasive esophagectomy: experimental study in a porcine model. Surg Endosc 27:3663-3670

13. Kenngott HG, Wagner M, Gondan M, Nickel F, Nolden M, Fetzer A, Weitz J, Fischer L, Speidel S, Meinzer H-P, Böckler D, Büchler MW, Müller-Stich BP (2013) Real-time image guidance in laparoscopic liver surgery: first clinical experience with 
a guidance system based on intraoperative CT imaging. Surg Endosc 28:933-940

14. Wagner M, Gondan M, Zollner C, Wunscher JJ, Nickel F, Albala L, Groch A, Suwelack S, Speidel S, Maier-Hein L, Muller-Stich BP, Kenngott HG (2016) Electromagnetic organ tracking allows for real-time compensation of tissue shift in image-guided laparoscopic rectal surgery: results of a phantom study. Surg Endosc 30:495-503

15. National Research Council (US) Committee for the Update of the Guide for the Care and Use of Laboratory Animals (2011) Guide for the care and use of laboratory animals, 8th edn. National Academies Press, Washington, DC

16. Clutton RE, Blissitt KJ, Bradley AA, Camburn MA (1997) Comparison of three injectable anaesthetic techniques in pigs. Vet Rec 141:140-146

17. Kenngott H, Neuhaus J, Müller-Stich B, Wolf I, Vetter M, Meinzer H-P, Köninger J, Büchler M, Gutt C (2008) Development of a navigation system for minimally invasive esophagectomy. Surg Endosc 22:1858-1865

18. Srimathveeravalli G, Leger J, Ezell P, Maybody M, Gutta N, Solomon SB (2013) A study of porcine liver motion during respiration for improving targeting in image-guided needle placements. Int J Comput Assist Radiol Surg 8:15-27

19. Kobr J, Kuntscher V, Treska V, Molacek J, Vobruba V, Fremuth J, Racek J, Trefil L, Kocova J (2008) Adverse effects of the high tidal volume during mechanical ventilation of normal lung in pigs. Bratisl Lek Listy 109:45-51

20. Roosens CD, Ama R, Leather HA, Segers P, Sorbara C, Wouters PF, Poelaert JI (2006) Hemodynamic effects of different lungprotective ventilation strategies in closed-chest pigs with normal lungs. Crit Care Med 34:2990-2996

21. Nolden M, Zelzer S, Seitel A, Wald D, Muller M, Franz AM, Maleike D, Fangerau M, Baumhauer M, Maier-Hein L, MaierHein KH, Meinzer HP, Wolf I (2013) The Medical Imaging Interaction Toolkit: challenges and advances: 10 years of open-source development. Int J Comput Assist Radiol Surg 8:607-620

22. Division of Medical and Biological Informatics of the German Cancer Research Center (2014) MITK: SegmentationInterpolationAlgorithm Class Reference. Available at: http://docs.mitk. org/2014.03/classmitk_1_1SegmentationInterpolationAlgorithm .html. Accessed 09 May 2015

23. Mirtich B (1996) Fast and accurate computation of polyhedral mass properties. J Graph Tools 1:31-50

24. Venables WN, Ripley BD (2002) modern applied statistics with S. Springer, Berlin

25. Muller SA, Blauer K, Kremer M, Thorn M, Mehrabi A, Meinzer HP, Hinz U, Metzger J, Buchler MW, Schmied BM (2010) Exact CT-based liver volume calculation including nonmetabolic liver tissue in three-dimensional liver reconstruction. J Surg Res 160:236-243

26. Frericks BB, Kiene T, Stamm G, Shin H, Galanski M (2004) CT-based liver volumetry in a porcine model: impact on clinical volumetry prior to living donated liver transplantation. RoFo: Fortschritte auf dem Gebiete der Rontgenstrahlen und der Nuklearmedizin 176:252-257

27. Frericks BB, Caldarone FC, Nashan B, Savellano DH, Stamm G, Kirchhoff TD, Shin HO, Schenk A, Selle D, Spindler W, Klempnauer J, Peitgen HO, Galanski M (2004) 3D CT modeling of hepatic vessel architecture and volume calculation in living donated liver transplantation. Eur Radiol 14:326-333

28. Bickel A, Loberant N, Bersudsky M, Goldfeld M, Ivry S, Herskovits M, Eitan A (2007) Overcoming reduced hepatic and renal perfusion caused by positive-pressure pneumoperitoneum. Arch Surg 142:119-125

29. Struthers AD, Cuschieri A (1998) Cardiovascular consequences of laparoscopic surgery. Lancet 352:568-570
30. Alexakis N, Gakiopoulou H, Dimitriou C, Albanopoulos K, Fingerhut A, Skalistira M, Patsouris E, Bramis J, Leandros E (2008) Liver histology alterations during carbon dioxide pneumoperitoneum in a porcine model. Surg Endosc 22:415-420

31. Yoshida M, Ikeda S, Sumitani D, Takakura Y, Yoshimitsu M, Shimomura M, Noma M, Tokunaga M, Okajima M, Ohdan H (2010) Alterations in portal vein blood $\mathrm{pH}$, hepatic functions, and hepatic histology in a porcine carbon dioxide pneumoperitoneum model. Surg Endosc 24:1693-1700

32. Muller SA, Pianka F, Schobinger M, Mehrabi A, Fonouni H, Radeleff B, Meinzer HP, Schmied BM (2011) Computer-based liver volumetry in the liver perfusion simulator. J Surg Res 171:87-93

33. Agusti M, Elizalde JI, Adalia R, Martinez-Palli G, Garcia-Valdecasas JC, Pique JM, Taura P (2001) The effects of vasoactive drugs on hepatic blood flow changes induced by $\mathrm{CO}_{2}$ laparoscopy: an animal study. Anesth Analg 93:1121-1126

34. Saenz Medina J, Asuero de Lis MS, Galindo Alvarez J, Villafruela Sanz J, Correa Gorospe C, Cuevas Sanchez B, Linares Quevedo AI, Paez Borda A, Pascual Santos J, Marcen Letosa R, Burgos Revilla J (2007) Modification of the hemodynamic parameters and peripheral vascular flow in a porcine experimental of model of laparoscopic nephrectomy. Arch Esp Urol 60:501-518

35. Smith MK, Mutter D, Forbes LE, Mulier S, Marescaux J (2004) The physiologic effect of the pneumoperitoneum on radiofrequency ablation. Surg Endosc 18:35-38

36. Hashikura Y, Kawasaki S, Munakata Y, Hashimoto S, Hayashi K, Makuuchi M (1994) Effects of peritoneal insufflation on hepatic and renal blood flow. Surg Endosc 8:759-761

37. Junghans T, Bohm B, Grundel K, Schwenk W, Muller JM (1997) Does pneumoperitoneum with different gases, body positions, and intraperitoneal pressures influence renal and hepatic blood flow? Surgery 121:206-211

38. Tunon MJ, Gonzalez P, Jorquera F, Llorente A, Gonzalo-Orden M, Gonzalez-Gallego J (1999) Liver blood flow changes during laparoscopic surgery in pigs. A study of hepatic indocyanine green removal. Surg Endosc 13:668-672

39. Windberger UB, Auer R, Keplinger F, Langle F, Heinze G, Schindl M, Losert UM (1999) The role of intra-abdominal pressure on splanchnic and pulmonary hemodynamic and metabolic changes during carbon dioxide pneumoperitoneum. Gastrointest Endosc 49:84-91

40. Klopfenstein CE, Morel DR, Clergue F, Pastor CM (1998) Effects of abdominal $\mathrm{CO}_{2}$ insufflation and changes of position on hepatic blood flow in anesthetized pigs. Am J Phys 275:H900-905

41. Moyano-Cuevas JL, Sanchez-Margallo FM, Maestre-Antequera J, Davila-Gomez L, Pagador JB, Sanchez-Peralta LF, Latorre R (2012) Effects of pneumoperitoneum and body position on the morphology of abdominal vascular structures analyzed in MRI. J Magn Reson Imaging 36:177-182

42. Lindberg F, Bergqvist D, Rasmussen I, Haglund U (1997) Hemodynamic changes in the inferior caval vein during pneumoperitoneum. An experimental study in pigs. Surg Endosc 11:431-437

43. Rosenthal RJ, Friedman RL, Chidambaram A, Khan AM, Martz J, Shi Q, Nussbaum M (1998) Effects of hyperventilation and hypoventilation on $\mathrm{PaCO}_{2}$ and intracranial pressure during acute elevations of intraabdominal pressure with $\mathrm{CO}_{2}$ pneumoperitoneum: large animal observations. J Am Coll Surg 187:32-38

44. Rosenthal RJ, Friedman RL, Kahn AM, Martz J, Thiagarajah S, Cohen D, Shi Q, Nussbaum M (1998) Reasons for intracranial hypertension and hemodynamic instability during acute elevations of intra-abdominal pressure: observations in a large animal model. J Gastrointest Surg 2:415-425

45. Parraga E, Lopez-Albors O, Sanchez-Margallo F, Moyano-Cuevas JL, Latorre R (2013) Effects of pneumoperitoneum and body 
position on the morphology of the caudal cava vein analyzed by MRI and plastinated sections. Surg Endosc 27:880-887

46. Sanchez-Margallo FM, Moyano-Cuevas JL, Latorre R, Maestre J, Correa L, Pagador JB, Sanchez-Peralta LF, Sanchez-Margallo JA, Uson-Gargallo J (2011) Anatomical changes due to pneumoperitoneum analyzed by MRI: an experimental study in pigs. Surg Radiol Anat 33:389-396

47. Finnerty CC, Mabvuure NT, Ali A, Kozar RA, Herndon DN (2013) The surgically induced stress response. JPEN J Parenter Enteral Nutr 37:21S-29S

48. Burton D, Nicholson G, Hall G (2004) Endocrine and metabolic response to surgery. Continuing Education in Anaesthesia. Crit Care Pain 4:144-147

49. Desborough JP (2000) The stress response to trauma and surgery. BJA 85:109-117

50. Lemke AJ, Brinkmann MJ, Pascher A, Steinmuller T, Settmacher U, Neuhaus P, Felix R (2003) Accuracy of the CT-estimated weight of the right hepatic lobe prior to living related liver donation (LRLD) for predicting the intraoperatively measured weight of the graft. RoFo: Fortschritte auf dem Gebiete der Rontgenstrahlen und der Nuklearmedizin 175:1232-1238

51. Karlo C, Reiner CS, Stolzmann P, Breitenstein S, Marincek B, Weishaupt D, Frauenfelder T (2010) CT- and MRI-based volumetry of resected liver specimen: comparison to intraoperative volume and weight measurements and calculation of conversion factors. Eur J Radiol 75:e107-111

52. Baskiran A, Kahraman AS, Cicek IB, Sahin T, Isik B, Yilmaz S (2018) Preoperative evaluation of liver volume in living donor liver transplantation. North Clin Istanb 5:1-5

53. Luecke T, Pelosi P, Quintel M (2007) Haemodynamic effects of mechanical ventilation. Der Anaesthesist 56:1242-1251

54. Jakob SM (2010) The effects of mechanical ventilation on hepatosplanchnic perfusion. Current opinion in critical care 16:165-168

55. Saner FH, Olde Damink SW, Pavlakovic G, Sotiropoulos GC, Radtke A, Treckmann J, Beckebaum S, Cicinnati V, Paul A (2010) Is positive end-expiratory pressure suitable for liver recipients with a rescue organ offer? J Crit Care 25:477-482

56. Saner FH, Olde Damink SW, Pavlakovic G, Sotiropoulos GC, Radtke A, Treckmann J, Beckebaum S, Cicinnati V, Paul A (2010) How far can we go with positive end-expiratory pressure (PEEP) in liver transplant patients? J Clin Anesth 22:104-109

57. Court FG, Wemyss-Holden SA, Morrison CP, Teague BD, Laws PE, Kew J, Dennison AR, Maddern GJ (2003) Segmental nature of the porcine liver and its potential as a model for experimental partial hepatectomy. Br J Surg 90:440-444

58. Radtke A, Sotiropoulos GC, Nadalin S, Molmenti EP, Schroeder T, Lang H, Saner F, Valentin-Gamazo C, Frilling A, Schenk A, Broelsch CE, Malago M (2007) Preoperative volume prediction in adult living donor liver transplantation: how much can we rely on it? Am J Transpl 7:672-679

59. Hoekstra LT, Ruys AT, Milstein DM, van Samkar G, van Berge Henegouwen MI, Heger M, Verheij J, van Gulik TM (2013) Effects of prolonged pneumoperitoneum on hepatic perfusion during laparoscopy. Ann Surg 257:302-307

60. Suzuki K, Epstein ML, Kohlbrenner R, Garg S, Hori M, Oto A, Baron RL (2011) Quantitative radiology: automated CT liver volumetry compared with interactive volumetry and manual volumetry. AJR Am J Roentgenol 197:W706-712

61. Nakayama Y, Li Q, Katsuragawa S, Ikeda R, Hiai Y, Awai K, Kusunoki S, Yamashita Y, Okajima H, Inomata Y, Doi K (2006) Automated hepatic volumetry for living related liver transplantation at multisection CT. Radiology 240:743-748

62. Salvalaggio PR, Baker TB, Koffron AJ, Fryer JP, Clark L, Superina RA, Blei AT, Nemcek A, Abecassis MM (2005) Liver graft volume estimation in 100 living donors: measure twice, cut once. Transplantation 80:1181-1185
63. Hiroshige S, Shimada M, Harada N, Shiotani S, Ninomiya M, Minagawa R, Soejima Y, Suehiro T, Honda H, Hashizume M, Sugimachi K (2003) Accurate preoperative estimation of livergraft volumetry using three-dimensional computed tomography. Transplantation 75:1561-1564

64. Dachman AH, MacEneaney PM, Adedipe A, Carlin M, Schumm LP (2001) Tumor size on computed tomography scans: is one measurement enough? Cancer 91:555-560

65. Kamel IR, Kruskal JB, Warmbrand G, Goldberg SN, Pomfret EA, Raptopoulos V (2001) Accuracy of volumetric measurements after virtual right hepatectomy in potential donors undergoing living adult liver transplantation. AJR Am J Roentgenol 176:483-487

66. Kawasaki S, Makuuchi M, Matsunami H, Hashikura Y, Ikegami T, Chisuwa H, Ikeno T, Noike T, Takayama T, Kawarazaki H (1993) Preoperative measurement of segmental liver volume of donors for living related liver transplantation. Hepatology (Baltimore, MD) 18:1115-1120

67. Satou S, Sugawara Y, Tamura S, Kishi Y, Kaneko J, Matsui Y, Kokudo N, Makuuchi M (2007) Three-dimensional computed tomography for planning donor hepatectomy. Transpl Proc 39:145-149

68. Ishifuro M, Horiguchi J, Nakashige A, Tamura A, Marukawa K, Fukuda H, Ono C, Akiyama Y, Kushima T, Ito K (2002) Use of multidetector row $\mathrm{CT}$ with volume renderings in right lobe living liver transplantation. Eur Radiol 12:2477-2483

69. Schroeder T, Malago M, Debatin JF, Goyen M, Nadalin S, Ruehm SG (2005) "All-in-one" imaging protocols for the evaluation of potential living liver donors: comparison of magnetic resonance imaging and multidetector computed tomography. Liver Transpl 11:776-787

70. Lee VS, Morgan GR, Teperman LW, John D, Diflo T, Pandharipande PV, Berman PM, Lavelle MT, Krinsky GA, Rofsky NM, Schlossberg P, Weinreb JC (2001) MR imaging as the sole preoperative imaging modality for right hepatectomy: a prospective study of living adult-to-adult liver donor candidates. AJR Am J Roentgenol 176:1475-1482

71. Sakamoto S, Uemoto S, Uryuhara K, Kim I, Kiuchi T, Egawa H, Inomata Y, Tanaka K (2001) Graft size assessment and analysis of donors for living donor liver transplantation using right lobe. Transplantation 71:1407-1413

72. Van Thiel DH, Hagler NG, Schade RR, Skolnick ML, Heyl AP, Rosenblum E, Gavaler JS, Penkrot RJ (1985) In vivo hepatic volume determination using sonography and computed tomography. Validation and a comparison of the two techniques. Gastroenterology $88: 1812-1817$

73. Soyer P, Roche A, Elias D, Levesque M (1992) Hepatic metastases from colorectal cancer: influence of hepatic volumetric analysis on surgical decision making. Radiology 184:695-697

74. Fulcher AS, Szucs RA, Bassignani MJ, Marcos A (2001) Right lobe living donor liver transplantation: preoperative evaluation of the donor with MR imaging. AJR Am J Roentgenol 176:1483-1491

75. Uzunkoy A, Ozardali I, Celik H, Demirci M (2012) The effect of carbon dioxide pneumoperitoneum on the severity of peritonitis. Ulusal travma ve acil cerrahi dergisi $=$ Turkish journal of trauma \& emergency surgery: TJTES 18:99-104

Publisher's Note Springer Nature remains neutral with regard to jurisdictional claims in published maps and institutional affiliations. 